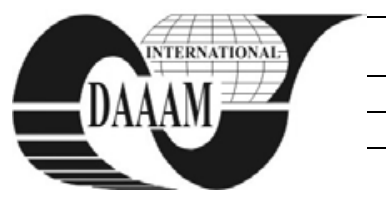

\title{
DIFFERENCES IN JOB CHARACTERISTICS BETWEEN LINE AND STAFF POSITIONS
}

\author{
HERNAUS, T[omislav] \& KOLAR, N[ikolina]
}

\begin{abstract}
Job design has a key role in organization design. It addresses various expectations, both individual and organizational. Due to existence of line and staff authority and responsibilities in organizations, the aim of the paper is to provide empirical results on differences in job characteristics between line and staff positions. Preliminary insights on necessary future steps are gained by analyzing jobs along several task characteristics.

Key words: task characteristics, job characteristics model, line positions, staff positions, job design
\end{abstract}

\section{INTRODUCTION}

Global and competitive business environment is forcing companies to optimize their operations at various levels. Emerging complexity of doing business puts a stronger emphasis not only on managers and organization design decisions, but on employees and their jobs as well. As the most important resource of organization, people should be put up front and assigned to motivating and challenging jobs.

Job design has a key role in organization design process. However, studies of job design theory and practice, which appeared in the 1960s, after a burst of research and writing during the 1970s, were put aside from the research mainstream. Although job design issues have been neglected for a long time, they still represent one of the most studied concepts in the organizational behavior field (Griffin \& McMahan, 1993).

Among many important approaches, The Job Characteristics Theory was recognized as the most dominant one to job design. It is a behavioral approach focused primarily on analyzing and measuring objective characteristics of employyees' jobs. The basic idea is to build into jobs those attributes that create conditions for high work motivation, satisfaction, and performance. The theory requires that characteristics of jobholders as well as of the jobs themselves be considered when work is designed (Hackman \& Oldham, 1980).

During the years, numerous job design models have been developed based on the measurement of objective job characteristics. However, the most influential one was The Job Characteristics Model (JCM) introduced by Hackman and Oldham (1976). They identified five core task characteristics (autonomy, task variety, task identity, task significance, feedback) that are primarily concerned with how the work itself is accomplished and the range and nature of tasks associated with a particular job (Morgeson \& Humphrey, 2006). In addition, they have developed the Job Diagnostic Survey (JDS), a data collection and measurement instrument, useful for determining a Motivating Potential Score (MPS) for each job.

JCM was extensively applied in various research contexts (e.g., different organizations, various industries, numerous occupations, different countries, etc.) and successfully tested for its rigor and relevance. It was confirmed that employees who were in positions with higher MPS were more satisfied and more motivated than employees positioned in jobs with lower MPS (Cummings \& Worley, 2005). Although JCM appeared in impressive number of studies, there is still a lack of research findings regarding differences in job characteristics between line and staff positions.

Line and staff positions or departments exist within virtually all organizations, but individuals who occupy these positions play significantly different roles. On one hand, people in line positions are typically more experienced, more oriented to the bottom line, and more intuitive in reaching decisions. They contribute directly to a creation or selling of company's products which means they are directly involved with the organization's core business processes. On the other hand, people in staff positions provide advice, recommendations, and research to line managers. They perform a technical and administrative service or provide special problem-solving expertise for other parts of the organization. Staff advisors contribute only indirectly to outcomes because they essentially represent extensions of the management function (Nadler \& Tushman, 1997).

Line and staff positions mainly differ in the scope of their responsibilities. Moreover, an employee in a line position may experience more autonomy than his or her colleague in a staff position, while a staff manager may enjoy some forms of feedback not available to a line manager (Gibson et al., 2011). Although it is obvious that significant differences in job design between line and staff positions exist, the difference has not been clearly empirically examined. Therefore, the aim of the paper is to provide empirical results on existing differences in job characteristics between line and staff positions. Preliminary insights on necessary future steps will be gained by analyzing jobs in one particular company.

\section{RESEARCH METHODOLOGY}

Case study approach with a survey research was applied on a large Croatian food-processing company with a functional organizational structure. A well-known JDS was used as a measurement instrument consisted of 19 questions, focused on five core task characteristics, as well as of 6 additional related to positional and individual characteristics of respondents. Prior to sending, the questionnaire was translated from English and validated in Croatian language $(\alpha>.7)$.

Questionnaires were distributed in June 2011 to the representative sample of 80 employees. Two weeks later, 62 valid responses were received from various parts of the organization (26 from line positions, and 36 from staff positions), accounting for an excellent $77.5 \%$ response rate. Most of the surveyed employees were younger than 30 (39.3\%) with less than 5 years of work experience (41.0\%). Both males and females were equally represented, while most of the respondents had either high school diploma (40.3\%) or a university degree (40.3\%).

Collected data regarding task characteristics was ordinal which allowed for a further inferential analysis. Subsampling method was applied and MPS was calculated for each employee, using the following formula:

SKILVAR+IDENTITY+SIGNIF x AUTON x FEEDBACK (1) 


\section{EMPIRICAL RESULTS}

It is expected that jobs differ along the different task characteristics. The same is valid for the observed company. In general, research findings show that job feedback is the highest evaluated task characteristic. This means that managers in the company conduct performance measurement on a regular basis, but also that jobs are designed properly so that results of conducted activities are clearly seen. In addition, it has been noticed that most surveyed employees have jobs that consisted of several very different tasks so there is no fear of having a monotonous job. However, task significance has been the lowest scored characteristic, meaning that people are not aware of the big picture and how their effort contributes to organizational goals in general.

Additionally, according to the literature, a difference between task characteristics of line and staff positions inside an organization is expected. In the particular survey, employees assigned in staff positions provided lower values of job characteristics than their line counterparts. As it is clearly shown in Table 1, staff jobs on average offered less autonomy, fewer distinct tasks, were not so significant and provided less feedback than line jobs. Also, the Motivating Potential Score for staff positions was lower than in line positions.

\begin{tabular}{|c|c|c|c|}
\hline $\begin{array}{c}\text { Task } \\
\text { characteristics }\end{array}$ & $\begin{array}{c}\text { All positions } \\
(n=62)\end{array}$ & $\begin{array}{c}\text { Line positions } \\
(n=26)\end{array}$ & $\begin{array}{c}\text { Staff positions } \\
(n=36)\end{array}$ \\
\hline AUTON & 3.76 & 3.88 & 3.67 \\
\hline VARIETY & 4.24 & 4.44 & 4.09 \\
\hline SIGNIF & 3.67 & 3.78 & 3.59 \\
\hline IDENTITY & 3.81 & 3.81 & 3.81 \\
\hline FEEDBACK & 4.36 & 4.44 & 4.30 \\
\hline MPS & $\mathbf{6 5 . 3 5}$ & $\mathbf{7 0 . 8 1}$ & $\mathbf{6 1 . 4 1}$ \\
\hline
\end{tabular}

Tab. 1. Descriptive results for three samples

However, additional analysis such as Levene's Test for Equality of Means showed a statistically significant mean difference only for task variety $(\mathrm{t}(62)=1.065, \mathrm{p}<.030)$. This means that the most significant difference between staff and line positions from the sample is diversity in their everyday work activities, while along the other task characteristics they are more or less similar.

Furthermore, correlation analysis showed that in staff positions there was a stronger and statistically more significant relationship between task variety and task significance $(\rho=.504$, $\mathrm{p}<.01)$ than concerning line positions $(\rho=.406, \mathrm{p}<.05)$. In other words, if tasks become more heterogeneous, employees in staff positions will appreciate their jobs more than their line colleagues.

Conducted analysis also revealed that an increase in job autonomy led to a more variety for staff positions $(\rho=.351$, $p<.05$ ), but on the other hand, also to more significant $(\rho=.426$, $\mathrm{p}<.05)$ and more complete $(\rho=.491, \mathrm{p}<.05)$ work activities for line positions.

Finally, a positive relationship is determined between task significance and job feedback for staff positions $(\rho=.393$, $\mathrm{p}<.05$ ), which means that the more significant task is, there will be more feedback from the job. In other words, one could conclude that jobs should provide better feedback which can hinder consequences of bad job performance.

\section{CONCLUSION}

Work cannot be done in a vacuum. Indeed, it is conducted through an organized effort of individuals in organizations. Nowadays, the design of work is inextricably bound up with the structures and processes of organizational systems more generally (Oldham \& Hackman, 2010). This means that a particular emphasis should be put on structural and process characteristics of an organization and the way how they impact individual job practices.

In this paper, we have focused on the first one because we noticed that structural issues such as staff versus line orientation, was severely neglected in previous research on job characteristics. Although numerous authors might have been aware of differences between those two different types of positions, very few of them tried to empirically analyze and clearly address existing differences.

The conducted survey was the first of a kind in the Central and Eastern Europe region. Although it revealed that real differences between staff and line positions are present only in task variety, its purpose was to provide a preliminary proof which will be a trigger for further research activities.

However, we should be aware of several possible limitations of this study. As foremost, Job Characteristics Model and its Job Diagnostic Survey used are narrowly focused only on task characteristics. Although they were in the heart of research activities during the last 35 years, it should be acknowledged that a job design concept has recently been extended to a richer and more comprehensive work design approach.

This broader approach not only considers traditional task characteristics, but it also takes into account several other such as knowledge characteristics, social characteristics, contextual characteristics, and group characteristics (e.g., Morgeson \& Humphrey, 2008). Furthermore, a very small sample and the fact that only one company was investigated makes the results hardly generalizable. Finally, individual characteristics should also be considered and included, because a job that motivates one individual does not necessarily motivate the other one. By taking into consideration those limitations, the results of this research can be further confirmed or discarded.

\section{REFERENCES}

Cummings, T. G. \& Worley, C. G. (2005). Organization Development and Change, South-Western College Pub, ISBN: 978-0324260601, Mason

Gibson, J., Ivancevich, J. M., Donnelly Jr., J. H., Konopaske, R. (2011). Organizations: Behavior, Structure, Processes, McGraw-Hill/Irwin, ISBN: 978-0078112669, New York

Griffin, R. W. \& MacMahan, G. C. (1993). Job Design: A Contemporary Review and Future Prospects, CEO Publication G 93-12 (232), Los Angeles

Hackman, J. R. \& Oldham, G. R. (1980). Work Redesign, Addison-Wesley, ISBN: 978-0201027792, Reading

Hackman, J. R. \& Oldham, G. R. (1976). Motivation through the Design of Work: Test of a Theory, Organizational Behavior and Human Performance, Vol. 16, pp. 250-279, ISSN: 0030-5073

Morgeson, F. P. \& Humphrey, S. E. (2006). The Work Design Questionnaire (WDQ): Developing and Validating a Comprehensive Measure for Assessing Job Design and the Nature of Work, Journal of Applied Psychology, Vol. 91, No. 6, pp. 1321-1339, ISSN: 0021-9010

Morgeson, F. P. \& Humphrey, S. (2008). Job and Team Design: Toward a More Integrative Conceptualization of Work Design, In: Research in Personnel and Human Resource Management, Vol. 27, Martocchio, J. (Ed.), pp. 39-92, Emerald Group Publishing Limited, ISBN: 978-1-84855004-09, London

Nadler, D. A., Tushman, M. L. (1997). Competing by Design The Power of Organizational Architecture, Oxford University Press, ISBN: 978-0195099171, New York

Oldham, G. R. \& Hackman, J. R. (2010). Not What Is Was and Not What It Wil Be: The Future of Job Design Research, Journal of Organizational Behavior, Vol. 31, pp. 463-479, ISSN: 0894-3796 